\title{
Pre-Hurricane Perceived Social Support Protects Against Psychological Distress: A Longitudinal Analysis of Low-Income Mothers
}

\author{
Sarah R. Lowe, Christian S. Chan, and Jean E. Rhodes \\ University of Massachusetts Boston
}

\begin{abstract}
Objective: In this study, we examined the influence of pre-disaster perceived social support on postdisaster psychological distress among survivors of Hurricane Katrina. Method: Participants $(N=386)$ were low-income mothers between 18 and 34 years of age at baseline $(M=26.4, S D=4.43)$. The majority (84.8\%) was African American; $10.4 \%$ identified as Caucasian, 3.2\% identified as Hispanic, and $1.8 \%$ identified as other. Participants were enrolled in an educational intervention study in 2004 and 2005. Those who had completed a 1-year follow-up assessment prior to Hurricane Katrina were reassessed approximately 1 year after the hurricane. Measures of perceived social support and psychological distress were included in pre- and post-disaster assessments. Using structural equation modeling and multiple mediator analysis, we tested a model wherein pre-disaster perceived social support predicted post-disaster psychological distress both directly and indirectly through its effects on pre-disaster psychological distress, exposure to hurricane-related stressors, and post-disaster perceived social support. We predicted that higher pre-disaster perceived social support would be predictive of lower pre-disaster psychological distress, lower hurricane-related stressors, and higher post-disaster perceived social support, and that these variables would, in turn, predict lower post-disaster psychologically distress. Results: Our analyses provide partial support for the hypothesized model. Although pre-disaster perceived social support did not exert a direct effect on post-disaster psychological distress, the indirect effects of all 3 proposed mediators were significant. Conclusions: Pre-disaster social support can decrease both exposure to natural disasters and the negative psychological effects of natural disaster exposure. These findings underscore the importance of bolstering the post-disaster social support networks of low-income mothers.
\end{abstract}

Keywords: natural disasters, social support, low-income populations, mothers

Hurricane Katrina was the worst natural disaster in recent U.S. history, and it accounted for nearly 2,000 deaths and the displacement of more than 650,000 people (Knabb, Rhome, \& Brown, 2006; U.S. Department of Commerce, 2006). The hurricane led to elevated levels of psychological distress among survivors, particularly those who were already struggling with difficult life circumstances (e.g., Galea et al., 2007; Kessler, Galea, Jones, \& Parker, 2006; Wang et al., 2007; Weisler, Barbee, \& Townsend, 2006). Even among the most vulnerable groups, however, there is often considerable variation in adaptive resources and psychological responses (Norris, Friedman, \& Watson, 2002; Norris, Friedman, Watson, Byrne, et al., 2002). In this study, we focus on one such resource-pre-disaster perceived social support-and the underlying processes by which it influences post-disaster psychological distress.

Sarah R. Lowe, Christian S. Chan, and Jean E. Rhodes, Department of Psychology, University of Massachusetts Boston.

The study was funded by National Institutes of Health Grant R01HD046162 and by the National Science Foundation, the MacArthur Foundation, and the Center for Economic Policy Studies at Princeton University. We thank Thomas Brock, MDRC (New York, New York), Christina Paxson, Elizabeth Fussell, and Mary Waters.

Correspondence concerning this article should be addressed to Jean E. Rhodes, Department of Psychology, University of Massachusetts Boston, Boston, MA 02125. E-mail: jean.rhodes@umb.edu

\section{Background}

Low-income, single, African American mothers are particularly vulnerable to post-disaster psychological difficulties (Brewin, Andrews, \& Valentine, 2000; Elliot \& Pais, 2006; Logan, 2006; Morrow, 1997; Solomon \& Green, 1992; Steinglass \& Gerrity, 1990). Their communities sustain relatively more damage from hurricanes (e.g., Elliot \& Pais, 2006; Logan, 2006; Peacock, Morrow, \& Gladwin, 1997; Spence, Lachlan, \& Griffin, 2007), and the stress of the disaster can amplify ongoing struggles with substandard childcare, poor educational options, racial oppression, and economic hardship (Edin \& Kefalas, 2007). Low-income and minority communities also have the greatest difficulties securing adequate resources and assistance in the aftermath of disasters (Bolin \& Bolton, 1986; Kaniasty \& Norris, 2009; Oliver-Smith, 2006). Moreover, women tend to bear the responsibility of caring for elders and small children in the aftermath of disasters (Norris, Baker, Murphy, \& Kaniasty, 2005; Solomon, Smith, Robins, \& Fischbach, 1987). Family-related tasks can render female hurricane survivors less able to attend to their own psychological needs (Gibbs, 1989; Morrow, 1997). Mothers of young children appear to be at particularly high risk for post-disaster adjustment problems (Bromet, Parkinson, Schulberg, Dunn, \& Gondek, 1982; Gibbs, 1989; Rubonis \& Bickman, 1991; Shore, Tatum, \& Vollmer, 1986), with single mothers experiencing the highest levels of family-related stress and psychological disorders (Morrow, 1997). 
It is important to note, however, that there is often considerable variation in survivors' adaptive coping, and that declines in functioning are neither consistent nor inevitable. Researchers (e.g., Brewin et al., 2000) have identified a range of protective factors, including better mental health functioning prior to the storm and social support, which seem to attenuate the psychological impact of natural disasters. Higher levels of social support, for example, have been associated with better post-disaster psychological functioning (Brewin et al., 2000; Norris \& Kaniasty, 1996; Vernberg, La Greca, Silverman, \& Prinstein, 1996). Indeed, the results of previous research suggest that support is particularly important to women in the aftermath of disasters (Norris et al., 2005; Solomon et al., 1987). Others have emphasized the particular importance of social networks to young, low-income, African American women, especially those caring for young children (e.g., Collins, 1987; Edin \& Kefalas, 2007; Rhodes, Ebert, \& Fischer, 1992; Shaffer, Coffino, Boelcke-Stennes, \& Masten, 2006; Stack, 1974).

Despite the important role of social support, the underlying pathways that account for its protective influence remain unclear. Moreover, most disaster studies have focused on post-disaster support when, in fact, pre-disaster social support, or changes in social support over time, might help to account for variations in outcomes. Research suggests, for example, that levels of social support shift throughout the recovery period and that pre-disaster social resources might affect post-disaster functioning (Kaniasty \& Norris, 2009). Along these lines, researchers have suggested that, rather than a static resource, social support is reactive to contextual influences. For example, initial support mobilization after natural disasters is often followed by deterioration in support resources (e.g., Norris et al., 2005). Similarly, Kaniasty and Norris (1993) found that both personal loss and community destruction were related to declines in support from levels prior to the disaster. Such declines in support may render some survivors more vulnerable to post-disaster psychological distress. Indeed, losses in social support have been shown to mediate the association between exposure and psychological distress (Smith \& Freedy, 2000).

Given the dynamic nature of social support, it is unfortunate that so few studies have examined the role of pre-disaster support levels on post-disaster outcomes. Earlier studies have relied primarily on post-Katrina samples (Abramson \& Garfield, 2006; Galea et al., 2007; Mills, Edmondson, \& Park, 2007; Weisler et al., 2006) or, as in the study by Kessler et al. (2006), have compared separate samples drawn from before and after the hurricane. More generally, the vast majority of disaster studies rely on post-disaster or retrospective data. Indeed, in a review by Norris, Friedman, Watson, Byrne, et al. (2002), only seven of the 160 studies included pre-disaster data. Although retrospective information provides some measure of pre-disaster functioning, it is likely to include measurement error, which leads to biased estimates of effects on post-disaster outcomes. For example, post-disaster experiences could influence responses to retrospective questions about pre-disaster social support. It is also difficult, in the absence of baseline data, to account for variability in adaptive functioning among survivors.

Drawing from pre- and post-Katrina data, and on the basis of extant literature, we hypothesized that there would be a significant loss of perceived social support and an increase in psychological distress from pre- to post-disaster. As depicted in Figure 1, we expected that pre-disaster perceived social support would influ-

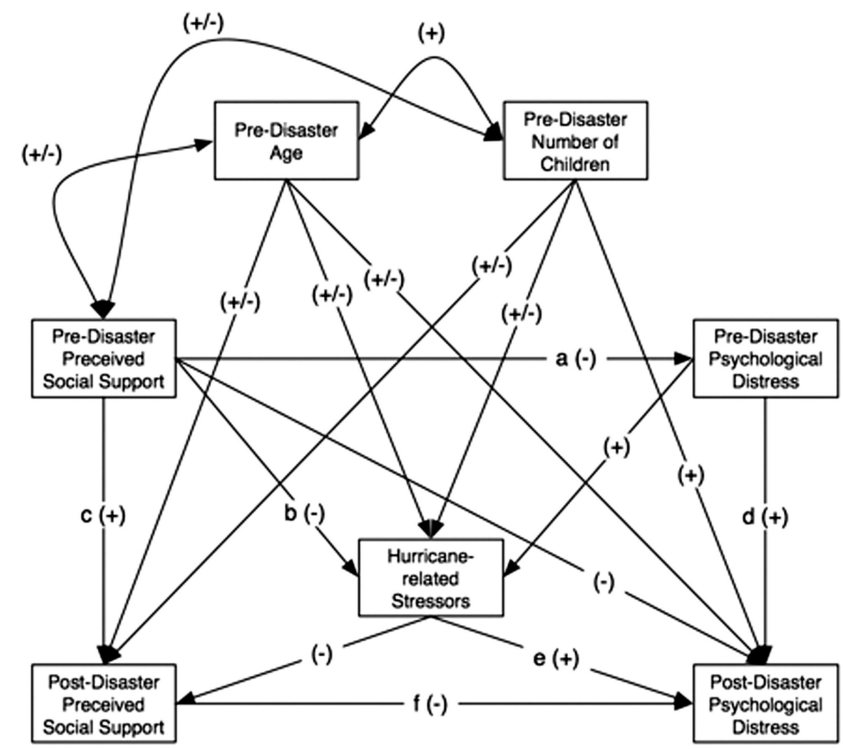

Figure 1. The hypothetical model. A plus sign indicates a hypothesized positive relationship; a negative sign indicates a hypothesized negative relationship; a plus/minus sign indicates no a priori prediction for direction.

ence post-disaster psychological distress directly, and also indirectly, through its influence on pre-disaster psychological distress (Path a), exposure to hurricane-related stressors (Path b), and post-disaster perceived social support (Path c). We describe each of these pathways below.

\section{Pathways From Pre-Disaster Perceived Social Support to Post-Disaster Psychological Distress}

First, we proposed that pre-disaster perceived social support would predict post-disaster psychological distress through its influence on pre-disaster psychological distress. Within this context, we predicted that pre-disaster support would bolster young women's adaptive coping and protect them from the adverse consequences of stress on psychological functioning (Brewin et al., 2000; Vernberg et al., 1996). Pre-disaster psychological distress, in turn, has been found to increase natural disaster survivors' risk for post-disaster psychopathology (e.g., Ginexi, Weihs, Simmens, \& Hoyt, 2000; Weems et al., 2007).

We also predicted that the support resources that individuals had at their disposal at the time of the natural disaster would affect the degree of trauma they experienced. It is clear from news accounts of Hurricane Katrina that the hardships it created were not distributed equally. Most wealthy families seem to have evacuated in advance of the storm and secured places to stay in hotels or with family and friends in other cities. Low-income families, in contrast, seem to have been disproportionately stranded in the city or in shelters after the storm, increasing the chance that they experienced deprivation, stress, and fear (Elliot \& Pais, 2006; Lavelle \& Feagin, 2006; Spence et al., 2007). However, it is also likely that there was heterogeneity in trauma exposure among low-income families. Although much of what determines exposure may be random, it may also be the case that support provisions (e.g., transportation, shelter, information, money) made it possible for 
some to evacuate, minimizing their exposure to traumatic events during and after the hurricane. Disaster studies have highlighted the importance of such tangible support (Bolin \& Bolton, 1986; Cook \& Bickman, 1990; Drabek \& Key, 1984), and Hobfoll and Parris Stevens (1990) have posited that social support may "directly prevent or limit resource loss and thereby insulate people from stressful circumstances" (p. 458). Gore (1985) has discussed the ability of people with high social support to mobilize resources in the face of stressors. Likewise, Kaniasty and Norris (2009) have posited that pre-disaster resources, including social support, can influence the degree of disaster exposure. Previous research has consistently demonstrated a dose-response effect of disaster exposure on post-disaster psychopathology (e.g., Goenjian et al., 2001; Shore et al., 1986). Thus, by mitigating exposure to hurricane-related stressors, pre-disaster social support is likely to have protected survivors from adverse psychological outcomes.

Lastly, we predicted that perceptions of pre-disaster social support would promote post-disaster psychological distress through its effects on social support in the aftermath of the disaster. More robust pre-disaster support may be both more reliable in the face of stress and more easily rebuilt and deployed in the aftermath of the disaster. Likewise, more stable individual characteristics, such as optimism, influence perceptions of social support (e.g., Dougall, Hyman, Hayward, McFeeley, \& Baum, 2001) and enable survivors to maintain positive relationships in the aftermath of adversity (Sarason, Sarason, \& Shearin, 1986). Survivors with high predisaster perceived social support may possess a general ability to maintain positive affect and reality checks against more catastrophic appraisals, thereby decreasing the effect of the disaster exposure on post-hurricane psychological distress (Cutrona \& Russell, 1990; Kessler, Price, \& Worthman, 1991; Lazarus \& Folkman, 1984).

In this study, we examined the role of pre-disaster social support in predicting survivors' psychological distress, and we included measures from both prior to and after Hurricane Katrina. Participants in the study were young, primarily African American mothers who survived Hurricane Katrina and, in some cases, Hurricane Rita. We hypothesized that there would be a significant loss of perceived social support and a significant increase in psychological distress from pre- to post-disaster. We also anticipated that pre-disaster perceived social support would influence post-disaster distress, both directly and through its influence on three variables: pre-disaster psychological distress, stressors experienced during the hurricane, and post-disaster perceived social support. Specifically, we predicted that pre-disaster perceived social support would be predictive of lower pre-disaster psychological distress, lower hurricane-related stressors, and higher post-disaster perceived social support, and that these variables would, in turn, predict lower post-disaster psychologically distress.

\section{Method}

\section{Participants and Procedure}

Participants were initially part of a study of low-income parents who had enrolled in three community colleges in the city of New Orleans in 2004-2005. The purpose of this initial study was to examine whether performance-based scholarships affected academic achievement, health, and well-being (Richburg-Hayes et al.,
2009). Starting in the spring semester of 2004, the colleges implemented programs specifically targeted to low-income parents. Participants were randomly assigned to either the Opening Doors program, which included $\$ 1,000$ scholarships for each of two semesters and extra academic advising, or to a control group that received no extra benefits. To be eligible for the study, students had to be between 18 and 34 years of age, be parents of at least one dependent child under 19 , have a household income under $200 \%$ of the federal poverty level, and have a high school diploma or equivalent. Students were invited to participate in the study through a general marketing and outreach campaign. At baseline, upon enrollment in the study and prior to random assignment, 1,019 participants provided primarily demographic information. By the time Hurricanes Katrina and Rita made landfall (on August 29, 2005, and September 24, 2005, respectively), 492 participants had been enrolled in the program long enough to complete a 12-month follow-up survey. Trained interviewers conducted the survey, which included measures of perceived social support and psychological distress, over the phone. After Hurricanes Katrina and Rita, between May 2006 and March 2007, 402 of these 492 participants $(81.7 \%)$ were successfully located and surveyed. The post-disaster survey, which was administered over the phone by trained interviewers, included the same questions as the 12-month follow-up survey as well as a module that collected detailed information about hurricane experiences. All participants provided written consent to be part of the original study and verbal consent to participate in the post-disaster survey.

In this study, Time 1 included data on demographic characteristics obtained at baseline and pre-disaster perceived social support and psychological distress levels obtained in a 12-month follow-up survey. Time 2 included post-disaster data on perceived social support and psychological distress obtained approximately one year after the disaster. In light of consistent findings of gender differences in psychological distress following natural disasters (e.g., Norris et al., 2005), the small subsample of male participants $(n=16)$ was dropped from the present study. The current analyses therefore drew on a sample of 386 women.

The demographic characteristics of the final sample were as follows. The mean age of the 386 women at baseline was 26.4 years $(S D=4.43)$, and their average number of children at the 1-year follow-up was $1.95(S D=1.06)$. All of the participants reported living in an area affected by Hurricane Katrina at the time that it hit the New Orleans area on August 29, 2005, and nearly half $(48.9 \%)$ reported living in areas affected by Hurricane Rita when it struck less than a month later. Most participants $(84.8 \%)$ identified as African American; 10.4\% identified as Caucasian, $3.2 \%$ identified as Hispanic, and $1.8 \%$ identified as other.

\section{Measures}

Perceived social support. We assessed perceptions of social support at Times 1 and 2 using eight items from the Social Provisions Scale (Cutrona \& Russell, 1987; Russell \& Cutrona, 1984). Perceived social support, defined as beliefs about the availability of support should a need arise, is generally considered a better predictor of mental health, including post-trauma distress, than the more structural measures of support (Fleming, Baum, Gisriel, \& Gatchel, 1982; Kaniasty \& Norris, 1993; Kaniasty, Norris, \& Murrell, 1990). The 24-item Social Provisions Scale was 
designed to assess six relational provisions identified by Weiss (1974). Instead of the full scale, which consists of six subscales (each with four items), an eight-item version was used. The shortened version included two items from four of the six original subscales: Social Integration (e.g., "I am with a group of people who think the same way I do about things"), Reassurance of Worth (e.g., "There are people who value my skills and abilities"), Guidance (e.g., "I have a trustworthy person to turn to if I have problems"), and Reliable Alliance (e.g., "There are people I know will help me if I really need it"). The full scale was not used to reduce the burden on participants, with the intention of increasing retention in the study. The retained items were selected a priori because they aligned with the goals of the Opening Doors program, which were to increase community college students' sense of social integration, connection, and guidance from their community colleges. Items were rated with on a 4-point Likert-type scale ranging from 1 (strongly disagree) to 4 (strongly agree), and half of the items were reverse scored. Cutrona (1989) provided evidence for the validity of the Social Provisions Scale among young mothers, and reliability (measured with Cronbach's alpha) for the full scale in a previous study was .92 (Cutrona, Russell, \& Rose, 1986). In the current study, reliability (measured with Cronbach's alpha) was .83 at Time 1 and .81 at Time 2 .

Psychological distress. The K6 scale, a six-item screening measure of nonspecific psychological distress common to all psychiatric disorders (Kessler et al., 2002), was used to assess pre- and post-disaster psychological distress. This scale has been shown to have good psychometric properties (Furukawa, Kessler, Slade, \& Andrews, 2003), and it has been used in previous research on the psychological functioning of Hurricane Katrina survivors (e.g., Galea et al., 2007; Wang et al., 2007). It includes items such as "During the past 30 days, about how often did you feel so depressed that nothing could cheer you up?" Respondents answer on a 5-point Likert-type scale ranging from 0 (none of the time) to 4 (all the time). Scale scores range from 0 to 24 , and the results of a previous validation study (Kessler et al., 2003) suggested that a scale score of 0-7 can be considered a probable absence of mental illness, a score of $8-12$ a probable mild or moderate mental illness, and a score of 13 a probable serious mental illness. The results of independent validation studies have shown high K6-scale scores to be strongly predictive of Diagnostic and Statistical Manual of Mental Disorders (4th ed.; American Psychiatric Association, 1994) anxiety-mood disorders (Kessler et al., 2002, 2003). Reliability of the K6 scale in this study (measured with Cronbach's alpha) was .70 at Time 1 and .80 at Time 2.

Hurricane-related stressors. Sixteen questions assessed stressors experienced during the hurricanes and the week that followed. The questions were drawn from a larger survey of the demographic and health characteristics, evacuation and hurricane experiences, and future plans of Hurricane Katrina evacuees. The Washington Post, the Kaiser Family Foundation, and the Harvard School of Public Health jointly designed the scale (Brodie, Weltzien, Altman, Blendon, \& Benson, 2006). Participants were asked to indicate whether they had experienced the following as a result of the hurricanes: (a) lacked enough fresh water to drink, (b) lacked enough food to eat, (c) felt their life was in danger, (d) lacked necessary medicine, (e) lacked necessary medical care, (f) had a family member who lacked necessary medical care, (g) lacked knowledge of safety of children, and (h) lacked knowledge of safety of other family members. These questions were asked for both Hurricane Katrina and Hurricane Rita, yielding
16 items in total. We created a composite score with the count of affirmative responses to these items $(\mathrm{KR}-20=0.84)$.

Demographic characteristics. In this study, we included participants' stated age at baseline and number of children at Time 1 as covariates. We selected these variables given findings that age (e.g., Brewin et al., 2000) and the presence of children (Bromet et al., 1982; Gibbs, 1989; Morrow, 1997) affect the risk for postdisaster psychopathology.

\section{Results}

\section{Missing Data and Normality}

Among the variables that we included in this study, the missing rate ranged from $0 \%$ to $3.6 \%$ on the item level. We conducted multiple imputation using the Amelia II software (Honaker, King, \& Blackwell, 2008) in $\mathrm{R}$ to handle the missing data. From the original data set, five complete data sets were imputed. The analyses presented below were each conducted independently across the five data sets. Each result represents an average of the five analyses. When necessary, we used Rubin's (1987) rule to combine results across imputed data sets and to calculate parameter estimates and standard errors.

We examined the univariate and multivariate normality of the data to determine whether assumptions of structural equation modeling were met. We found no severe violation of normality in terms of skewness $($ all $<1.5)$ and kurtosis $(<3.0)$ on any of the variables. Multivariate normality, however, was not achieved (Mardia's coefficient $=8.30$ ). Log-transformations were conducted on the following variables, on the basis of their relatively high critical ratio on skewness and kurtosis (i.e., both $>1.9$ ), to reduce the impact of outliers and nonnormality: number of children, pre- and post-hurricane psychological distress, and number of hurricanerelated stressors. The resulting Mardia's coefficient was -0.92 , which indicates nonsignificant kurtosis (i.e., <1.96).

\section{Descriptive Statistics}

As indicated above, $81.7 \%$ of the participants were retained between the two waves of data collection. Participants who completed both pre- and post-disaster questionnaires were compared with those who completed only the pre-disaster questionnaire. The results of $t$ tests and chi-square tests, which included controls for multiple tests, indicate that the two groups of participants did not differ significantly on any of the comparison variables, including pre-hurricane age, number of children, race, household income, perceived social support, and psychological distress.

Multivariate analyses of variance indicated no significant differences in psychological distress on the basis of racial and ethnic groups, marital status, and experimental condition (i.e., Opening Doors program vs. control). In addition, we detected no significant correlations between household income and pre- and posthurricane psychological distress and perceived social support scale scores. On the other hand, post hoc analyses (Tukey) did reveal higher perceived social support among Caucasians than African Americans $(p<.01)$. Hence, we conducted multigroup comparison when testing the hypothesized path model to ensure betweengroups invariance (see below). In Table 1, we present the means, 
Table 1

Means, Standard Deviations, and Zero-Order Correlations Among Variables

\begin{tabular}{|c|c|c|c|c|c|c|c|c|c|}
\hline Variable & $M$ & $S D$ & 1 & 2 & 3 & 4 & 5 & 6 & 7 \\
\hline 1. Age & 26.42 & 4.43 & - & & & & & & \\
\hline 2. No. of children & 1.95 & 1.06 & $.33^{* * * *}$ & - & & & & & \\
\hline 3. Pre-disaster social support & 18.36 & 3.88 & .06 & -.09 & - & & & & \\
\hline 4. Pre-disaster psychological distress & 5.55 & 4.07 & .04 & .06 & $-.27^{* * * *}$ & - & & & \\
\hline 5. Post-disaster social support & 17.50 & 3.86 & -.07 & $-.16^{* *}$ & $.38^{* * * * *}$ & -.09 & - & & \\
\hline 6. Post-disaster psychological distress & 6.68 & 5.21 & .09 & -.01 & $-.14^{* *}$ & $.36^{* * * *}$ & $-.28^{* * * * *}$ & - & \\
\hline 7. Hurricane-related stressors & 3.80 & 3.33 & $.19^{\text {***** }}$ & $.16^{* * *}$ & $-.15^{* *}$ & $.15^{* *}$ & $-.16^{* * *}$ & $.28^{* * * *}$ & - \\
\hline
\end{tabular}

Note. $N=386$. All results include imputed values, prior to log transformation.

${ }^{* * *} p<.01 .{ }^{* * * * *} p<.001$.

standard deviations, and zero-order correlations for the variables in the study.

\section{Pre-Disaster and Post-Disaster Comparisons}

Consistent with our prediction, paired-samples $t$ tests indicated that there was a significant reduction in perceived social support from Time 1 to Time $2(M=18.36, S D=3.88$ vs. $M=17.50$, $S D=3.86), t(385)=3.90, p<.001, d=0.20$, as well as a significant increase in psychological distress from Time 1 to Time $2(M=5.55, S D=4.07$ vs. $M=6.68, S D=5.21), t(385)=$ $-4.16, p<.001, d=-0.22$. The percentage of participants with a probable mental illness based on their reported psychological distress (i.e., K6 scale score $>7$ ) increased from $23.0 \%$ to $37.4 \%$. McNemar's test indicated that the increase was statistically significant $(p<.001)$. The percentage of participants who moved from below to above the cutoff point of psychological distress (i.e., worsened conditions) was $23.6 \%$, whereas $9.0 \%$ shifted from above to below the cutoff point (i.e., improved conditions), and $67.4 \%$ remained unchanged after the hurricanes.

\section{Path Analysis}

We tested the hypothesized path model (see Figure 1) using the maximum likelihood method in the AMOS 16.0 program (Arbuckle, 2007) across all five imputed data sets. All model fit results were the average of the five separate analyses. Following the recommendations of $\mathrm{Hu}$ and Bentler (1998), we set the cutoff of acceptable model fit at $<.08$ for the root mean square error of approximation (RMSEA) and $>.95$ for the comparative fit index (CFI). The initial estimation of the model resulted in a good fit to the data, $\chi^{2}(3, N=386)=.649, n s ; C F I=1.00 ;$ RMSEA $=.000$ $(90 \%$ CI $[.000, .037])$; Akaike information criterion $($ AIC $)=$ 64.65. Statistical power for the hypothesis of close fit was 1.00 (as calculated with R software; Preacher \& Coffman, 2006). ${ }^{1}$ As a next step, we trimmed nonsignificant paths $(p>.10)$. The resulting path model, which we present in Figure 2, provided a good fit to the data, $\chi^{2}(9, N=386)=10.78, n s ; C F I=.99 ; R M S E A=$ $.022(90 \%$ CI $[.000, .064]) ; A I C=62.78$. Statistical power for the hypothesis of close fit was 1.00 . The difference of fit between the hypothesized model and the trimmed model was not statistically significant, $\Delta \chi^{2}(6)=10.13, n s$, indicating that the more parsimonious model was not of a worse fit than the hypothesized model. The final trimmed model accounted for $17.3 \%$ of the variance in post-disaster distress.

\section{Test of Alternative Model}

To further examine the contribution of pre-disaster perceived social support data, we tested the hypothesized model without the path from pre-disaster perceived social support to hurricanerelated stressors. In other words, this model assumed no association between one's perception of social support before the hurricane and the number of stressors resulting from the hurricane. This model was a good fit to the data, $\chi^{2}(4, N=386)=6.73, n s ; C F I=$ $.99 ;$ RMSEA $=.040$ (90\% CI $[.000, .095]) ; A I C=68.54$. Compared with the hypothesized model, however, this alternative model was a worse fit, $\Delta \chi^{2}(1)=5.89, p<.05$. As a next step, we trimmed the nonsignificant paths previously trimmed from the hypothesized model to compare model fit of the two trimmed models. The resulting model was a good fit to the data, $\chi^{2}(10, N=$ $386)=19.84, p<.01 ; C F I=.96 ;$ RMSEA $=.050$ (90\% CI [.015, $.083]) ; A I C=69.84$. Compared with the trimmed version of the hypothesized model, this model was a worse fit, $\Delta \chi^{2}(1)=9.06$, $p<.01$.

\section{Testing the Significance of the Indirect Effect}

To further test the significance of the total and specific indirect effects of pre-disaster perceived social support on post-disaster psychological distress, we used the bootstrap resampling procedure on a multiple mediator model, with pre-disaster perceived social support as the independent variable; pre-disaster psychological distress, post-disaster perceived social support, and hurricanerelated stressors as the mediators; and post-disaster psychological distress as the dependent variable. We used bootstrapping-a nonparametric resampling procedure - to test this multiple mediation model. Bootstrapping is recommended over the more traditional Sobel test or causal steps approaches to test indirect effects because it has relatively higher statistical power while maintaining control over Type I error rate (MacKinnon, Lockwood, Hoffman,

\footnotetext{
${ }^{1}$ A multigroup comparison between categories of African American participants $(84.8 \%$ of sample) and Caucasian participants $(10.4 \%$ of sample) was conducted. Results of multigroup comparison, with all regression parameters constrained as equal across group, detected no significant difference, $\Delta \chi^{2}(14)=17.50, n s$, suggesting that the model fit the data from the two groups similarly. Similarly, no significant difference was found when African Americans were compared with all the other racial/ethnic groups combined. Hence, the racial and ethnic groups were combined in all the remaining analyses.
} 


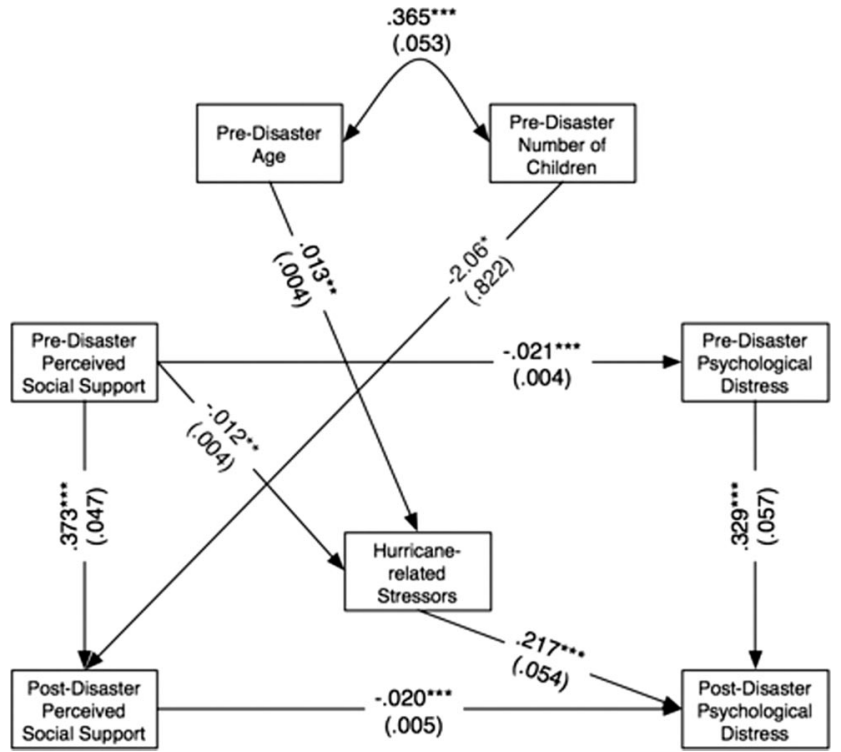

Figure 2. Final path model for post-hurricane mental distress. Numbers represent unstandardized path coefficients. Standard errors are in parentheses. $N=386 .{ }^{*} p<.05 .{ }^{* *} p<.01 .{ }^{* * *} p<.001$.

West, \& Sheets, 2002; MacKinnon, Lockwood, \& William, 2004; for a general discussion on modern methods to test mediation, see also MacKinnon, Fairchild, \& Fritz, 2007). Bootstrapping, with the available data, generates a reference distribution, which can be used for significance testing and confidence interval estimation (Mooney \& Duval, 1993). In accordance with the recommended guidelines of Preacher and Hayes (2008) and Shrout and Bolger (2002), we used the following bootstrap resampling procedure to determine the distribution of parameter estimates and to test the significance level of the indirect effects. First, we created 2,000 bootstrap samples using the each of the imputed data sets by random sampling with replacement. Second, we tested the multiple mediation model of pre-disaster perceived social support (independent variable) on post-disaster psychological distress (dependent variable)—-through pre-disaster psychological distress, postdisaster perceived social support, and hurricane-related stressors (with age and number of children as covariates) - 2,000 times with these bootstrap samples using SPSS with a macro provided by Preacher and Hayes; this resulted in 2,000 estimates of each path coefficient. Third, output from the 2,000 estimates of each path coefficient provided estimates of the indirect effects of pre-disaster perceived social support on post-disaster psychological distress via multiplication of 2,000 sets of path coefficients from pre-disaster perceived social support to pre-disaster psychological distress (Path a in Figure 1) and from pre-disaster psychological distress to post-disaster psychological distress (Path d); from pre-disaster perceived social support to post-disaster perceived social support (Path c) and from post-disaster perceived social support to postdisaster psychological distress (Path f); and from pre-disaster perceived social support to hurricane-related stressors (Path b) and from hurricane-related stressors to post-disaster psychological distress (Path e). According to Shrout and Bolger, if the 95\% confidence interval for these estimates of an indirect effect does not contain zero, it can be concluded that the indirect effect is statistically significant at the .05 level.

The total and direct effects of pre-disaster perceived social support on post-disaster psychological distress were $B=-0.013$ $(p<.01)$ and $B=0.004(n s)$, respectively. We present the results of the total and specific indirect effects in Table 2. Because none of the confidence intervals included zero, the results support the hypotheses that the pre-disaster levels of perceived social support predicted post-disaster levels of psychological distress through pre-disaster psychological distress, hurricane-related stressors, and post-disaster perceived social support.

\section{Discussion}

The results of this study indicate that survivors' perceived social support significantly decreased from pre- to post-disaster and that

Table 2

Indirect Effect of Pre-Disaster Social Support on Post-Disaster Psychological Distress Through Pre-Disaster Psychological Distress, Post-Disaster Social Support, and Hurricane-Related Stressors

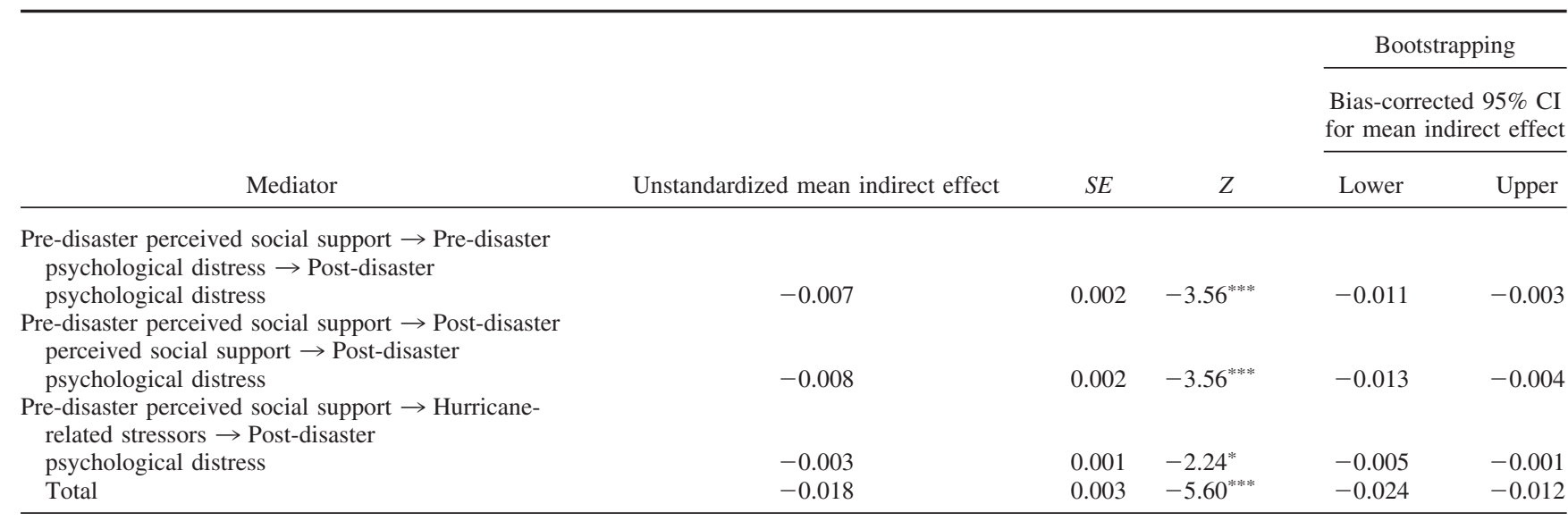

Note. $\quad N=386 ; 2,000$ bootstrap sample. All results include imputed and log-transformed values. Age and number of children are statistically controlled ${ }^{*} p<.05 . \quad{ }^{* * * *} p<.001$ 
psychological distress significantly increased. In addition, although pre-disaster social support did not have a direct effect on post-disaster psychological distress, the hypothesized model fit well with the data. Moreover, pre-disaster social support had modest indirect effects on post-disaster psychological distress, and these effects were through the hypothesized variables (psychological distress, hurricane-related stressors, and post-disaster perceived social support). Specifically, participants who perceived greater pre-disaster social support had less pre-disaster psychological distress, experienced fewer hurricane-related stressors, and perceived more support in the aftermath of the hurricane. These factors, in turn, were associated with less post-disaster psychological distress.

Taken together, the results provide evidence for the importance of pre-disaster levels of perceived social support in the psychological outcomes among disaster survivors and shed light onto the processes through which these effects occur. Perceiving low levels of pre-disaster support seems to render individuals more vulnerable to adverse psychological consequences of disaster-related stressors. In contrast, adequate support appears to decrease disaster victims' exposure to hurricane-related stressors. Of course, social support can prevent exposure only to the extent that there is adequate knowledge of the impending disaster. Whereas hurricanes, including Katrina and Rita, are typically preceded by warnings and evacuation decrees, other disasters, such as earthquakes, are often unpredictable. In these cases, perceived social support may have larger effects on appraisals of stressors than on actual exposure, helping to regulate the intensity of emotional reactions to the event. Appraisals and emotional regulation, in turn, are stronger predictors of traumatic stress than the exposure itself (Basoglu, Kilic, Salcioglu, \& Livanou, 2004; Ozer, Best, Lipsey, \& Weiss, 2003; Salcioglu, Basoglu, \& Livanou, 2003). As such, the pathway between perceived social support and trauma exposure should be tested in the context of unavoidable disasters, controlling for the effects of both subjective appraisals and objective trauma characteristics.

The hypothesized model had a better fit with the data than an alternative in which the pathway from pre-hurricane perceived support to exposure was removed, suggesting that pre-hurricane support may reduce survivors' exposure to certain stressful events during the hurricanes and their immediate aftermath. Network members may have provided housing, transportation, and other resources that enabled young mothers to escape the full brunt of the storm. Of course, it remains plausible that psychological distress led to decreased perceptions of support, rather than the reverse. Likewise, post-disaster distress may have influenced reports of hurricane-related stressors (Kaniasty \& Norris, 2008). In future studies, researchers should draw on multiple waves of post-disaster data to investigate reciprocal relationships among variables over time.

This study benefited from the availability of pre-Katrina data, which enabled us to explore the role of pre-disaster perceived social support and to provide robust evidence that mental health declines coincided with the hurricane. An additional strength of the study is its focus on a vulnerable, nonclinical sample of survivors that was disproportionally affected by Hurricane Katrina. Moreover, by documenting a significant decline in social support, we provide further evidence for Kaniasty and Norris's (2004, 2009) social support deterioration model.
Also consistent with previous theory, declines in perceived social support were predictive of increases in psychological distress among survivors (Hobfoll \& Parris Stevens, 1990). PreKatrina data also illuminated the continuity in pre- to post-disaster levels of psychological distress levels. This is consistent with studies that have found that pre-disaster levels of depression were the most important factor in determining the severity of postdisaster depression (Knight, Gatz, Heller, \& Bengtson, 2000; Seplaki, Goldman, Weinstein, \& Lin, 2006).

The findings also have important implications for planning of post-disaster psychological care services. Efforts to identify and provide timely, evidence-based services to those with preexisting psychological vulnerabilities could potentially prevent adverse post-disaster outcomes and attenuate progression into more serious mental illness.

There were, however, several notable limitations to this study. Our index of social support did not distinguish among types of perceived social support (e.g., emotional, informational, tangible), limiting our ability to discern whether specific forms of support led to fewer hurricane-related stressors. It would have also been helpful to obtain additional descriptive information about the composition of the participants' social networks-a factor that was shown to influence depressive symptomatology among Hurricane Andrew survivors (Haines, Beggs, \& Hurlbert, 2008). Data on the support that participants provided to others in the aftermath of disaster would also be beneficial in future research, as social demands could increase stress and influence psychological outcomes (Lazarus \& Folkman, 1984).

Our reliance on a screening tool of nonspecific distress further limits the scope of the study. An analysis of the effects of perceived social support on specific psychiatric problems commonly observed in the aftermath of a disaster (e.g., posttraumatic stress disorder, depression, grief) could reveal differential associations informative to the planning of therapeutic interventions for disaster survivors. Likewise, the index of hurricane-related stressors was based on self-reports and did not assess information on lifethreatening traumatic experiences (e.g., exposure to violent winds, being injured, witnessing injury). Given that the pattern of findings may have changed had these variables been included in the model, especially if more specific measures of psychiatric illness were used, the findings need to be interpreted with caution.

Future research should also examine how individual differencesincluding gender, race, optimism, and biological markers-might affect associations between pre-disaster support and post-disaster psychological distress (Kilpatrick et al., 2007). Finally, future research should use additional waves of post-disaster data to examine long-term trajectories and mediators of functioning. Latent growth curve modeling of change would permit researchers to explore whether the indirect influence of pre-disaster social support on post-disaster psychological distress persists over time.

The results of this study have implications for interventions and policies aimed at reducing disaster-related psychological distress. Efforts to mobilize and fortify social support can help to attenuate individuals' exposure to natural disaster and reduce adverse outcomes in their aftermath. In addition to bolstering social support, specialized post-disaster mental health services should be made more available to treat the specific forms of psychological distress that often occur, including post-traumatic stress, depression, and grief responses. Taken together, such efforts can reduce or even 
prevent some of the difficulties that arise among survivors of natural disasters.

\section{References}

Abramson, D., \& Garfield, R. (2006). On the edge: Children and families displaced by Hurricane Katrina and Rita-A looming medical and mental health crisis. Retrieved from http://www.childrenshealthfund.org

American Psychiatric Association. (1994). Diagnostic and statistical manual of mental disorders (4th ed.). Washington, DC: Author.

Arbuckle, J. L. (2007). Amos 16.0 [Computer software]. Spring House, PA: Amos Development

Basoglu, M., Kilic, C., Salcioglu, E., \& Livanou, M. (2004). Prevalence of posttraumatic stress disorder and comorbid depression in earthquake survivors in Turkey: An epidemiological study. Journal of Traumatic Stress, 17, 133-141.

Bolin, R., \& Bolton, P. (1986). Race, religion, and ethnicity in disaster recovery (Monograph No. 42). Boulder, CO: University of Colorado, Institute for Behavioral Science, Natural Hazard Research and Applications Information Center, Environment and Behavior.

Brewin, C. R., Andrews, B., \& Valentine, J. D. (2000). Meta-analysis of risk factors for posttraumatic stress disorder in trauma-exposed adults. Journal of Consulting and Clinical Psychology, 68, 748-766.

Brodie, M., Weltzien, E., Altman, D., Blendon, R. J., \& Benson, J. M. (2006). Experiences of Hurricane Katrina evacuees in Houston shelters: Implications for future planning. American Journal of Public Health, 96, 1402-1408

Bromet, E. J., Parkinson, D. K., Schulberg, H. C., Dunn, L. O., \& Gondek, P. C. (1982). Mental health of residents near the Three Mile Island Reactor: A comparative study of selected groups. Journal of Preventive Psychiatry, 1, 225-274.

Collins, P. H. (1987).). The meaning of motherhood in Black culture and Black mother/daughter relationships. Sage: Scholarly Journal of Black Women, 4, 3-10.

Cook, J. D., \& Bickman, L. (1990). Social support and psychological symptomatology following a natural disaster. Journal of Traumatic Stress, 3, 541-556.

Cutrona, C. E. (1989). Ratings of social support by adolescents and adult informants: Degree of correspondence and prediction of depressive symptoms. Journal of Personality and Social Psychology, 57, 723-730.

Cutrona, C. E., \& Russell, D. (1987). The provisions of social relationships and adaptation to stress. In W. H. Jones \& D. Perlman (Eds.), Advances in personal relationships (Vol. 1, pp. 37-67). Greenwich, CT: JAI Press.

Cutrona, C. E., \& Russell, D. W. (1990). Type of social support and specific stress: A theory of optimal matching. In B. R. Sarason, I. G. Sarason, \& G. R. Pierce (Eds.), Social support: An interactional view (pp. 319-366). New York, NY: Wiley.

Cutrona, C., Russell, D., \& Rose, J. (1986). Social support and adaptation to stress by the elderly. Psychology and Aging, 1, 47-54.

Dougall, A. L., Hyman, K. B., Hayward, M. C., McFeeley, S., \& Baum, A. (2001). Optimism and traumatic stress: The importance of social support and coping. Journal of Applied Social Psychology, 31, 223-245.

Drabek, T. E., \& Key, W. M. (1984). Conquering disaster: Family recovery and long-term consequences. New York, NY: Irvington.

Edin, K., \& Kefalas, M. (2007). Promises I can keep: Why poor women put motherhood before marriage. Berkeley, CA: University of California Press.

Elliot, J. R., \& Pais, J. (2006). Race, class, and Hurricane Katrina: Social differences in human response to disaster. Social Science Research, 35, 295-321.

Fleming, R., Baum, A., Gisriel, M. M., \& Gatchel, R. J. (1982). Mediating influences of social support on stress at Three Mile Island. Journal of Human Stress, 8, 14-22.

Furukawa, T. A., Kessler, R. C., Slade, T., \& Andrews, G. (2003). The performance of the K6 and K10 screening scales for psychological distress in the Australian. Psychological Medicine, 33, 357-362.

Galea, S., Brewin, C. R., Gruber, M., Jones, R. T., King, D. W., King, L. A., , . Kessler, R. C. (2007). Exposure to hurricane-related stressors and mental illness after Hurricane Katrina. Archive of General Psychiatry, 64, 1427-1434.

Gibbs, M. S. (1989). Factors in the victim that mediate between disaster and psychopathology: A review. Journal of Traumatic Stress, 2, 489513 .

Ginexi, E. M., Weihs, K., Simmens, S. J., \& Hoyt, D. R. (2000). Natural disaster and depression: A prospective investigation of reactions to the 1993 Midwest floods. American Journal of Community Psychology, 28, 495-518.

Goenjian, A. K., Molina, L., Steinberg, A. M., Fairbanks, L. A., Alvarez, M. L., Goenjian, H. A., \& Pynoos, R. S. (2001). Posttraumatic stress and depressive reactions among Nicaraguan adolescents after Hurricane Mitch. American Journal of Psychiatry, 158, 788-794.

Gore, S. (1985). Social support and styles of coping with stress. In S. Cohen \& S. L. Syme (Eds.), Social support and health (pp. 263-278). Orlando, FL: Academic Press.

Haines, V. A., Beggs, J. J., \& Hulbert, J. S. (2008). Contextualizing health outcomes: Do effects of network structure differ for men and women? Sex Roles, 59, 164-175.

Hobfoll, S. E., \& Parris Stevens, M. A. (1990). Social support during extreme stress: Consequences and intervention. In B. R. Sarason, I. G Sarason, \& G. R. Pierce (Eds.), Social support: An interactional view (pp. 454-481). New York, NY: Wiley.

Honaker, J., King, G., \& Blackwell, M. (2008). Amelia II: A program for missing data [Computer software]. Retrieved from http://gking.harvard edu/amelia/

Hu, L., \& Bentler, P. M. (1998). Fit indices in covariance structure modeling: Sensitivity to underparameterized model misspecification. Psychological Methods, 3, 424-453.

Kaniasty, K., \& Norris, F. H. (1993). A test of the social support deterioration model in the context of natural disaster. Journal of Personality and Social Psychology, 64, 395-408.

Kaniasty, K., \& Norris, F. H. (2004). Social support in the aftermath of disasters, catastrophes, and acts of terrorism: Altruistic, overwhelmed, uncertain, antagonistic, and patriotic communities. In R. Ursano \& C. Fullerton (Eds.), Bioterrorism: Psychological and public health interventions. Cambridge, England: Cambridge University Press.

Kaniasty, K., \& Norris, F. (2008). Longitudinal linkages between perceived social support and posttraumatic stress symptoms: Sequential roles of social causation and social selection. Journal of Traumatic Stress, 21, 274-281.

Kaniasty, K., \& Norris, F. H. (2009). Distinctions that matter: Received social support, perceived social support, and social embeddedness after disasters. In Y. Neria, S. Galea, \& F. Norris (Eds.), Mental health consequences of disasters (pp. 175-201). New York, NY: Cambridge University Press.

Kaniasty, K. Z., Norris, F. H., \& Murrell, S. A. (1990). Received and perceived social support following natural disaster. Journal of Applied Social Psychology, 20, 85-114

Kessler, R. C., Andrews, G., Colpe, L. J., Hiripi, E., Mroczek, D. K., Normand, S. L., . . Zaslavsky, A. M. (2002). Short screening scales to monitor population prevalances and trends in nonspecific psychological distress. Psychological Medicine, 32, 959-976.

Kessler, R. C., Barker, P. R., Colpe, L. J., Epstein, J. F., Groerer, J. C., Hiripi, E., ... Zaslavsky, A. M. (2003). Screening for serious mental illness in the general population. Archives of General Psychiatry, 60, $184-189$.

Kessler, R. C., Galea, S., Jones, R. T., \& Parker, H. A. (2006). Mental illness and suicidality after Hurricane Katrina. Bulletin of the World Health Organization, 84, 930-939. 
Kessler, R. C., Price, R. H., \& Worthman, C. B. (1991). Social factors in psychopathology: Stress, social support, and coping processes. Annual Review of Psychiatry, 36, 531-572.

Kilpatrick, D. G., Koenen, K. C., Ruggiero, K. J., Acierno, R., Galea, S., Resnick, H. S., ... Gelernter, J. (2007). The serotonin transporter genotype and social support and moderation of posttraumatic stress disorder and depression in hurricane-exposed adults. American Journal of Psychiatry, 164, 1693-1699.

Knabb, R. D., Rhome, J. R., \& Brown, D. P. (2006). Tropical Cyclone Report: Hurricane Katrina. Retrieved from http://nhc.noaa.gov/pdf/ TCR-AL122005_Katrina.pdf

Knight, B. G., Gatz, M., Heller, K., \& Bengtson, V. L. (2000). Age and emotional response to the Northridge earthquake. Psychology and Aging, 15, 627-634.

Lavelle, K., \& Feagin, J. R. (2006). Hurricane Katrina: The race and class debate. Retrieved from http://www.monthlyreview.org/0706lavelle.htm

Lazarus, S., \& Folkman, R. S. (1984). Stress, appraisal, and coping. New York, NY: Springer.

Logan, J. R. (2006). The impact of Katrina: Race and class in stormdamaged neighborhoods. Unpublished manuscript. Spatial Structures in the Social Sciences Initiative, Brown University, Providence, Rhode Island.

MacKinnon, D. P., Fairchild, A. J., \& Fritz, M. S. (2007). Mediation analysis. Annual Review of Psychology, 58, 593-614.

MacKinnon, D. P., Lockwood, C. M., Hoffman, J. M., West, S. G., \& Sheets, V. (2002). A comparison of methods to test mediation and other intervening variable effects. Psychological Methods, 7, 83-104.

MacKinnon, D. P., Lockwood, C. M., \& Williams, J. (2004). Confidence limits for the indirect effect: Distribution of the product and resampling methods. Multivariate Behavioral Research, 39, 99-128.

Mills, M. A., Edmondson, D., \& Park, C. L. (2007). Trauma and stress response among hurricane Katrina evacuees. American Journal of Public Health, 97, 116-123.

Mooney, C. Z., \& Duval, R. D. (1993). Bootstrapping: A nonparametric approach to statistical inference. Newbury Park, CA: Sage.

Morrow, B. H. (1997). Stretching the bonds: The families of Andrew. In W. G. Peacock, B. H. Morrow, \& H. Gladwin (Eds.), Hurricane Andrew: Ethnicity, gender, and the sociology of disasters (pp. 141-170). New York, NY: Routledge.

Norris, F. H., Baker, C. K., Murphy, A. D., \& Kaniasty, K. (2005). Social support mobilization and deterioration after Mexico's 1999 flood: Effects of context, gender and time. American Journal of Community Psychology, 36, 15-28.

Norris, F., Friedman, M., \& Watson, P. (2002). 60,000 disaster victims speak: Part II. Summary and implications of the disaster mental health research. Psychiatry, 65, 240-260.

Norris, F., Friedman, M., Watson, P., Byrne, C., Diaz, E., \& Kaniasty, K. (2002). 60,000 disaster victims speak: Part I. An empirical review of the empirical literature, 1981-2001. Psychiatry, 65, 207-239.

Norris, F. H., \& Kaniasty, K. (1996). Received and perceived social support in times of stress: A test of the social support deteriorationdeterrence model. Journal of Personality and Social Psychology, 7, $498-511$.

Oliver-Smith, A. (2006). Disasters and forced migration in the 21st century. Retrieved from http://understandingkatrina.ssrc.org/Oliver-Smith .pdf/

Ozer, E. J., Best, S. R., Lipsey, T. L., \& Weiss, D. S. (2003). Predictors of posttraumatic stress disorder and symptoms in adults: A meta-analysis. Psychological Bulletin, 129, 52-73.

Peacock, W. B., Morrow, B. H., \& Gladwin, H. (1997). Hurricane Andrew: Ethnicity, gender, and the sociology of disasters. New York, NY: Routledge.

Preacher, K. J., \& Coffman, D. L. (2006). Computing power and minimum sample size for RMSEA [Computer software]. Available from http:// www.quantpsy.org

Preacher, K. J., \& Hayes, A. F. (2008). Asymptotic and resampling strategies for assessing and comparing indirect effects in multiple mediator models. Behavior Research Methods, 40, 879-891.

Rhodes, J. E., Ebert, L., \& Fischer, K. (1992). Natural mentors: An overlooked resource in the social networks of African-American adolescent mothers. American Journal of Community Psychology, 20, 445461.

Richburg-Hayes, L., Brock, T., LeBlanc, A., Paxson, C., Rouse, C. E., \& Barrow, L. (2009). Rewarding persistence: Effects of a performancebased scholarship program for low-income parents. New York, NY: MDRC.

Rubin, D. B. (1987). Multiple imputation for nonresponse in surveys. New York, NY: Wiley.

Rubonis, A. V., \& Bickman, L. (1991). Psychological impairment in the wake of disaster: The disaster-psychopathology relationship. Psychological Bulletin, 109, 384-399.

Russell, D., \& Cutrona, C. (1984, August). The provision of social relationships and adaptation to stress. Paper presented at the American Psychological Association, Toronto, Ontario, Canada.

Salcioglu, E., Basoglu, M., \& Livanou, M. (2003). Long-term psychological outcome for non-treatment-seeking earthquake survivors in Turkey. Journal of Nervous and Mental Disease, 191, 154-160.

Sarason, I. G., Sarason, B. R., \& Shearin, E. N. (1986). Social support as an individual difference variable: Its stability, origins, and relational aspects. Journal of Personality and Social Psychology, 50, 845-855.

Seplaki, C. L., Goldman, N., Weinstein, M., \& Lin, Y.-H. (2006). Before and after the 1999 Chi-Chi earthquake: Traumatic events and depressive symptoms in an older population. Social Science \& Medicine, 62, 3121-3132.

Shaffer, A., Coffino, B., Boelcke-Stennes, K., \& Masten, A. A. (2006). From urban girls to resilient women: Studying adaptation across development in the context of adversity. In B. J. R. Leadbeater \& N. Way (Eds.), Urban girls revisited: Building strengths (pp. 53-74). New York, NY: New York University Press.

Shore, J. H., Tatum, E. L., \& Vollmer, W. M. (1986). Psychiatric reaction to disaster: The Mount St. Helen's experience. American Journal of Psychiatry, 143, 590-595.

Shrout, P. E., \& Bolger, N. (2002). Mediation in experimental and nonexperimental studies: New procedures and recommendations. Psychological Methods, 7, 422-445.

Smith, B. W., \& Freedy, J. R. (2000). Psychosocial resource loss as a mediator of the effects of flood exposure on psychological distress and physical symptoms. Journal of Traumatic Stress, 13, 349-357.

Solomon, S. D., \& Green, B. L. (1992). Mental health effects of natural and human-made disasters. PTSD Research Quarterly, 3, 1-7.

Solomon, S. D., Smith, E. M., Robins, L. N., \& Fischbach, R. L. (1987). Social involvement as a mediator of disaster-induced stress. Journal of Applied Social Psychology, 17, 1092-1112.

Spence, P. R., Lachlan, K. A., \& Griffin, D. R. (2007). Crisis communication, race, and natural disasters. Journal of Black Studies, 37, 539554.

Stack, C. (1974). All our kin: Strategies for survival in a black community. New York, NY: Harper \& Row.

Steinglass, P., \& Gerrity, E. (1990). Natural disasters and post-traumatic stress disorder: Short-term versus long-term recovery in two disasteraffected communities. Journal of Applied Social Psychology, 20, 17461765.

U.S. Department of Commerce. (2006). Gulf coast recovery: 17 months after the hurricanes. Washington, DC: Economics and Statistics Administration. Retrieved from http://www.economics.noaa.gov/library/ documents/economics_for_coastal_marine_management/gulf-coastrecovery-esa.doc 
Vernberg, E. M., La Greca, A. M., Silverman, W. K., \& Prinstein, M. J. (1996). Prediction of posttraumatic stress symptoms in children after Hurricane Andrew. Journal of Abnormal Psychology, 105, 237-248.

Wang, P. S., Gruber, M. J., Powers, R. E., Schoenbaum, M., Speier, A. H., Wells, K. B., \& Kessler, R. C. (2007). Mental health service use among Hurricane Katrina survivors in the eight months after the disaster. Psychiatric Services, 58, 1403-1411.

Weems, C. F., Pina, A. A., Costa, N. M., Watts, S. E., Taylor, L. K., \& Cannon, M. F. (2007). Predisaster trait anxiety and negative affect predict posttraumatic stress in youths after Hurricane Katrina. Journal of Consulting and Clinical Psychology, 75, 154-159.
Weisler, R. H., Barbee, J. G., \& Townsend, M. H. (2006). Mental health and recovery in the Gulf Coast after Hurricane Katrina and Rita. Journal of the American Medical Association, 296, 585-588.

Weiss, R. S. (1974). The provisions of social relationships. In R. Zick (Ed.), Doing unto others: Joining, molding, conforming, helping, loving (pp. 17-26). Englewood Cliffs, NJ: Prentice Hall.

Received December 1, 2008

Revision received November 2, 2009

Accepted November 3, 2009

\section{E-Mail Notification of Your Latest Issue Online!}

Would you like to know when the next issue of your favorite APA journal will be available online? This service is now available to you. Sign up at http://notify.apa.org/ and you will be notified by e-mail when issues of interest to you become available! 